\title{
InAlGaN/GaN HEMTs at Cryogenic Temperatures
}

\author{
Ezgi Dogmus ${ }^{1}$, Riad Kabouche ${ }^{1}$, Sylvie Lepilliet ${ }^{1}$, Astrid Linge ${ }^{1}$, Malek Zegaoui ${ }^{1}$, \\ Hichem Ben-Ammar ${ }^{2}$, Marie-Pierre Chauvat ${ }^{2}$, Pierre Ruterana ${ }^{2}$, Piero Gamarra ${ }^{3}$, \\ Cédric Lacam ${ }^{3}$, Maurice Tordjman ${ }^{3}$ and Farid Medjdoub ${ }^{1, *}$ \\ 1 Institute of Electronics, Microelectronics and Nanotechnology (IEMN), Av. Poincaré, \\ Villeneuve d'Ascq 59652, France; ezgi.dogmus@ed.univ-lille1.fr (E.D.); \\ riad.kabouche@etudiant.univ-lille1.fr (R.K.); sylvie.lepilliet@iemn.univ-lille1.fr (S.L.); \\ astrid.linge@iemn.univ-lille1.fr (A.L.); malek.zegaoui@iemn.univ-lille1.fr (M.Z.) \\ 2 Centre de recherche sur les Ions, les MAtériaux et la Photonique, Caen 14000, France; \\ hichem.ben-ammar@ensicaen.fr (H.B.-A.); chauvat@ensicaen.fr (M.-P.C.); pierre.ruterana@ensicaen.fr (P.R.) \\ 3 Thales Research and Technology, 3-5lab, Av. Augustin Fresnel, RD128, Palaiseau 91767, France; \\ piero.gamarra@3-5lab.fr (P.G.); cedric.lacam@3-5lab.fr (C.L.); maurice.tordjman@3-5lab.fr (M.T.) \\ * Correspondence: farid.medjdoub@iemn.univ-lille1.fr; Tel.: +33-320-19-7840
}

Academic Editor: Geok Ing Ng

Received: 30 April 2016; Accepted: 17 June 2016; Published: 22 June 2016

\begin{abstract}
We report on the electron transport properties of two-dimensional electron gas confined in a quaternary barrier InAlGaN/AlN/GaN heterostructure down to cryogenic temperatures for the first time. A state-of-the-art electron mobility of $7340 \mathrm{~cm}^{2} \cdot \mathrm{V}^{-1} \cdot \mathrm{s}^{-1}$ combined with a sheet carrier density of $1.93 \times 10^{13} \mathrm{~cm}^{-2}$ leading to a remarkably low sheet resistance of $44 \Omega / \square$ are measured at $4 \mathrm{~K}$. A strong improvement of Direct current (DC) and Radio frequency (RF) characteristics is observed at low temperatures. The excellent current and power gain cutoff frequencies $\left(f_{\mathrm{T}} / f_{\max }\right)$ of $65 / 180 \mathrm{GHz}$ and $95 / 265 \mathrm{GHz}$ at room temperature and $77 \mathrm{~K}$, respectively, using a $0.12 \mu \mathrm{m}$ technology confirmed the outstanding 2DEG properties.
\end{abstract}

Keywords: InAlGaN HEMT; cryogenic temperature; microwave

\section{Introduction}

$\mathrm{Al}(\mathrm{In}) \mathrm{GaN} / \mathrm{GaN}$-based high-electron-mobility transistors (HEMTs) have shown great promise for high frequency and high power microwave applications owing to their highly conductive two dimensional electron gas (2DEG) combined with a high breakdown field. In order to achieve high-speed GaN devices, lattice-matched InAlN barrier layers were proposed, with which 2DEG carrier density is much higher than AlGaN barrier HEMTs, namely due to the spontaneous polarization $[1,2]$. However, the growth of InAlN is limited by the high immiscibility between AlN and InN, which results in alloy scattering and elevated interface roughness due to clustering in InAlN. Despite the implementation of an ultrathin AlN spacer to reduce the alloy scattering and enhance the 2DEG confinement [3], the growth of the ternary alloy remains challenging. On the other hand, a quaternary InAlGaN compound is attractive as a barrier layer since it allows easier adjustment of the band gap and strain state with suitable $\mathrm{Al} / \mathrm{In}$ ratios [4-10]. Recently, we have reported InAlGaN/AlN/GaN heterostructure HEMTs with a sub-10-nm ultrathin quaternary barrier with a state-of-the-art electron mobility of $1800 \mathrm{~cm}^{2} \cdot \mathrm{V}^{-1} \cdot \mathrm{s}^{-1}$ and a sheet carrier density of $1.9 \times 10^{13} \mathrm{~cm}^{-2}$ at room temperature [11]. In this paper, the 2DEG properties of this specific heterostructure are investigated for a temperature range of $4-400 \mathrm{~K}$. Furthermore, InAlGaN/AlN/GaN HEMTs using $120 \mathrm{~nm}$ gate lengths $\left(L_{\mathrm{G}}\right)$ have been fabricated and characterized at room temperature (RT) and low temperature (77K). 


\section{Device Fabrication}

The structure was grown by low-pressure metal-organic chemical vapor deposition (MOCVD) on a 4 in $\mathrm{SiC}$ substrate and consists of a $1.6 \mu \mathrm{m}$ carbon compensated buffer layer, a 150-nm-thick GaN channel, a 1.2-nm-thick AlN interlayer, a 6.4-nm-thick $\operatorname{In}_{0.18} \mathrm{Al}_{0.70} \mathrm{Ga}_{0.12} \mathrm{~N}$ layer and a 2-nm-thick in situ SiN cap layer (Figure 1a). Transmission electron microscopy (TEM) analysis revealed a high quality two-dimensional growth of the InAlGaN and AlN layers on $\mathrm{GaN}$ with smooth interfaces as can be seen in Figure 1b. Details on growth conditions and further structural characterizations of the $\mathrm{Si}_{x} \mathrm{~N}_{y} / \mathrm{InAlGaN} / \mathrm{AlN} / \mathrm{GaN}$ HEMT heterostructure can be found elsewhere [11].

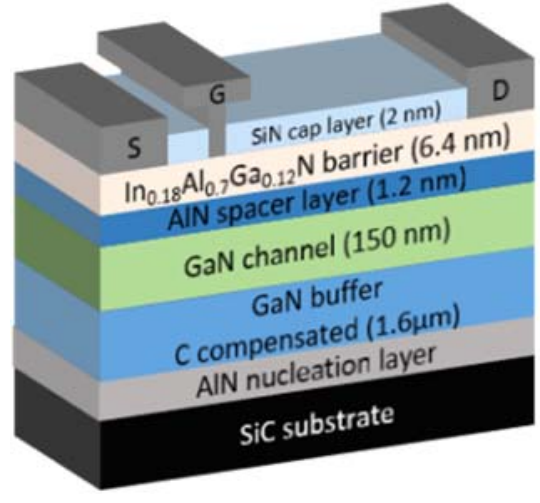

(a)

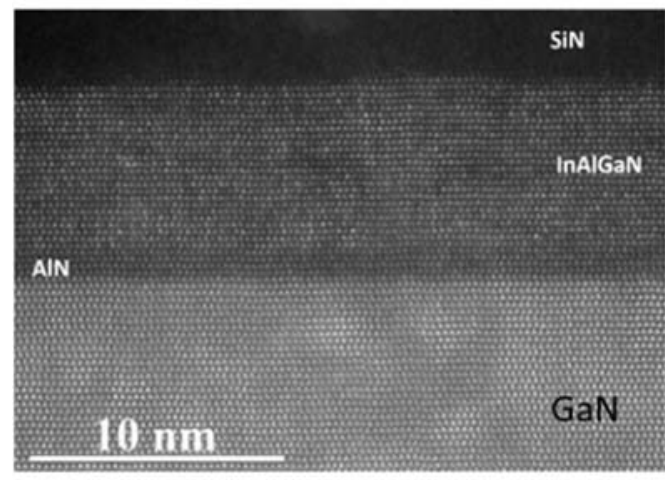

(b)

Figure 1. Schematic cross-section (a) and TEM image (b) of $\mathrm{Si}_{x} \mathrm{~N}_{y} / \mathrm{InAlGaN} / \mathrm{AlN} / \mathrm{GaN}$ HEMTs.

\section{Results}

Cryogenic temperature Hall effect measurements were assessed in a vacuum chamber by using a helium gas closed-cycle cryostat and Lakeshore 776HMS measurement system. Figure 2 shows the Hall electron mobility, sheet carrier density and sheet resistance of the HEMT structure over the 4-400 K range. At liquid helium temperature $(4 \mathrm{~K})$, a state-of-the-art 2DEG mobility of $7340 \mathrm{~cm}^{2} \cdot \mathrm{V}^{-1} \cdot \mathrm{s}^{-1}$ combined with a sheet carrier density of $1.93 \times 10^{13} \mathrm{~cm}^{-2}$ was measured, resulting in a remarkably low sheet resistance of $44 \Omega$ / . For InAlN/AlN/GaN heterostructures, the carrier mobility was reported to be determined by a temperature-independent interface roughness scattering mechanism, while above $200 \mathrm{~K}$ the optical and acoustical phonon scattering become dominant [12]. Consequently, in this study, the excellent combination of electron mobility and a high 2DEG carrier density below $200 \mathrm{~K}$ is attributed to very low interface roughness and optimized quaternary alloy barrier thickness. Furthermore, the in situ $\mathrm{Si}_{x} \mathrm{~N}_{y}$ cap layer, which provides handling strain relaxation as well as serving as an early surface passivation layer, enhances the 2DEG properties.

In order to emphasize the effect of crystalline quality on 2DEG properties, Table 1 presents a comparison of room-temperature 2DEG characteristics of the $\mathrm{Si}_{x} \mathrm{~N}_{y} / \mathrm{InAlGaN} / \mathrm{AlN} / \mathrm{GaN}$ heterostructures with similar designs grown on $\mathrm{SiC}$ and sapphire substrates. Higher electron mobility and sheet carrier density yielding much lower sheet resistance is observed for the HEMT structure grown on $\mathrm{SiC}$ compared to those on sapphire. The better epitaxial growth quality is attributed to the lower defect density and higher thermal conductivity [13]. 


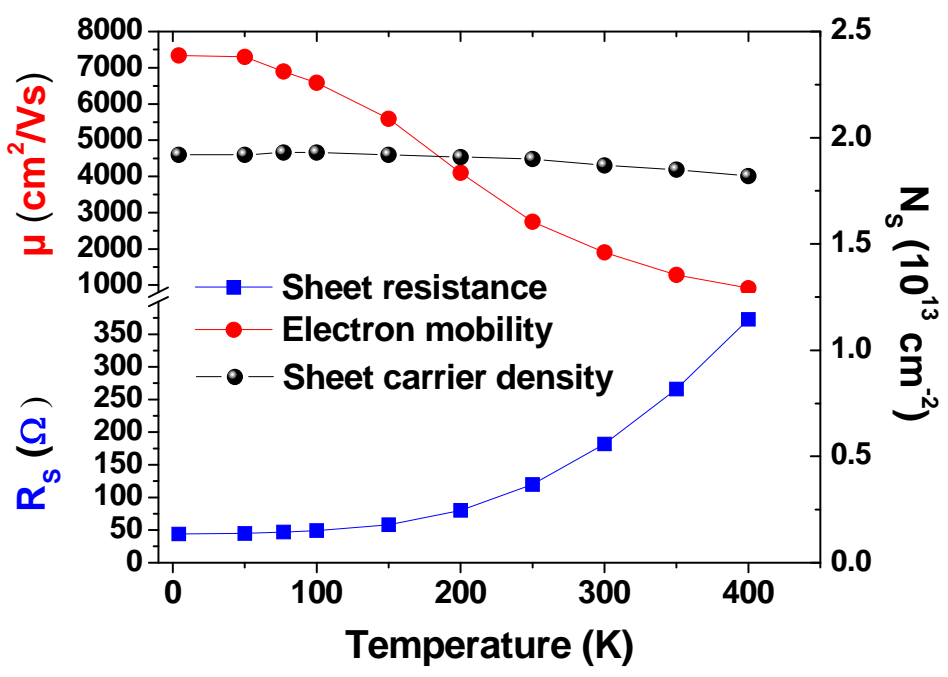

Figure 2. Sheet resistance (in blue), Hall mobility (in red) and sheet carrier density (in black) of the $\mathrm{Si}_{x} \mathrm{~N}_{y} / \mathrm{InAlGaN} / \mathrm{AlN} / \mathrm{GaN}$ HEMT heterostructure as a function of temperature.

Table 1. Comparison of room temperature 2DEG properties of the $\mathrm{Si}_{x} \mathrm{~N}_{y} / \mathrm{InAlGaN} / \mathrm{AlN} / \mathrm{GaN}$ heterostructures with similar designs grown on sapphire and $\mathrm{SiC}$ substrates.

\begin{tabular}{cccc}
\hline Substrate & $\begin{array}{c}\text { Electron Mobility } \\
\left(\mathbf{c m}^{\mathbf{2}} \cdot \mathbf{V}^{-\mathbf{1}} \cdot \mathbf{s}^{\mathbf{- 1}}\right)\end{array}$ & $\begin{array}{c}\text { Sheet Carrier Density } \\
\left(\mathbf{c m}^{-\mathbf{2}}\right)\end{array}$ & Sheet Resistance $(\Omega / \square)$ \\
\hline Sapphire & 1060 & $1.74 \times 10^{13}$ & 340 \\
$\mathrm{SiC}$ & 1800 & $1.93 \times 10^{13}$ & 191 \\
\hline
\end{tabular}

$\mathrm{Si}_{x} \mathrm{~N}_{y} / \mathrm{InAlGaN} / \mathrm{AlN} / \mathrm{GaN}$ HEMTs grown on $\mathrm{SiC}$ were fabricated using a gate length of $120 \mathrm{~nm}$ in order to reflect the remarkable 2DEG characteristics. Device processing has been performed by using a Ti/ $\mathrm{Al} / \mathrm{Ni} / \mathrm{Au}$ metal stack for ohmic contacts on an InAlGaN barrier followed by a rapid thermal annealing at $875{ }^{\circ} \mathrm{C}$, resulting in contact resistances of $0.4 \Omega \cdot \mathrm{mm}$. T-shaped Ni/Au gate Schottky contacts were defined by e-beam lithography. Nitrogen quadruple implantation ( $20 \mathrm{keV}$, $50 \mathrm{keV}, 100 \mathrm{keV}$ and $150 \mathrm{keV}$ ) was used for device isolation. A $0.3 \mu \mathrm{m}$ gate-source and $2 \mu \mathrm{m}$ gate-drain spacing were employed with a gate width of $50 \mu \mathrm{m}$.

\section{$D C$ and RF Characteristics at RT and $77 \mathrm{~K}$}

Agilent E5273A and E8361A network analyzers were used in order to assess the cryogenic temperature DC and RF characteristics of the HEMT devices in a vacuumed cryogenic probing system equipped with a nitrogen gas closed-cycle cryostat and on-wafer probes. The drain current-voltage and transfer characteristics of a $0.12 \times 50 \mu \mathrm{m}^{2} \mathrm{InAlGaN} / \mathrm{GaN}$ HEMT at $77 \mathrm{~K}$ and RT are presented in Figure 3. The saturated DC output current density at $V_{\mathrm{GS}}=+1 \mathrm{~V}$ increased from $1.3 \mathrm{~A} / \mathrm{mm}$ to $1.6 \mathrm{~A} / \mathrm{mm}$ as the operation temperature decreased from RT to $77 \mathrm{~K}$ as shown in Figure 3a. In addition, at $77 \mathrm{~K}$ the on-resistance $\left(R_{\mathrm{ON}}\right)$ decreased by $20 \%$ relative to its RT value. Similarly, at $77 \mathrm{~K}$ the extrinsic transconductance $\left(g_{\mathrm{m}, \text { ext }}\right)$ peak showed an increase of about $40 \%$ from its RT value and reached $500 \mathrm{mS} / \mathrm{mm}$ (Figure $3 \mathrm{~b}$ ). As a matter of fact, the improvement in 2DEG mobility and the decrease in sheet resistance from RT to $77 \mathrm{~K}$, leading to an effective increase of the electron velocity under the gate, results in enhanced DC characteristics at lower operation temperature [14].

Figure $4 \mathrm{a}, \mathrm{b}$ reveal the current-gain $\left(f_{\mathrm{T}}\right)$ and power-gain $\left(f_{\max }\right)$ extrinsic cut-off frequencies at RT and $77 \mathrm{~K}$ extrapolated from the current gain $\mathrm{H} 21$ and the unilateral power gain $\mathrm{U}$ at $V_{\mathrm{GS}}=-3 \mathrm{~V}$ and $V_{\mathrm{DS}}=8 \mathrm{~V}$, respectively. The values of $f_{\mathrm{T}} / f_{\max }$ were derived to be $65 / 180 \mathrm{GHz}$ and $95 / 265 \mathrm{GHz}$ at $\mathrm{RT}$ and $77 \mathrm{~K}$, respectively. The frequency performances are clearly limited by the 
parasitic access resistances and thus ohmic contact resistances should be decreased in order to achieve higher cut-off frequencies.

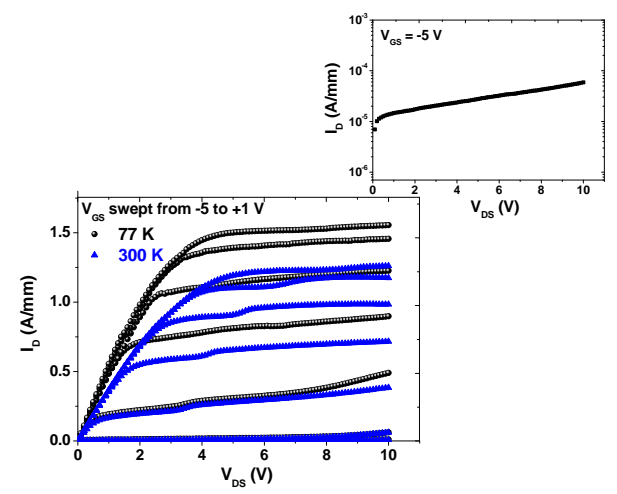

(a)

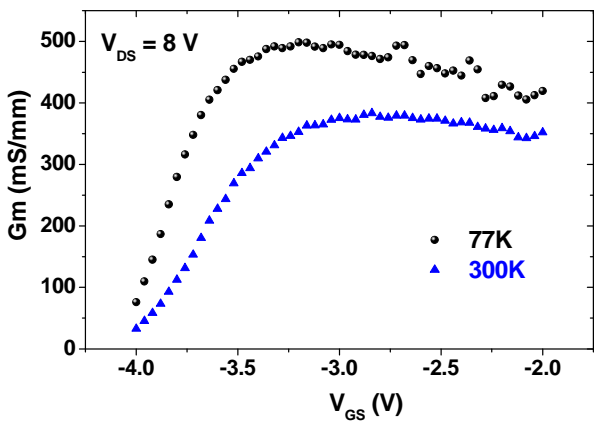

(b)

Figure 3. $I_{\mathrm{D}}-V_{\mathrm{DS}}$ characteristics (the inset shows the sub-threshold behavior up to $10 \mathrm{~V}$ in semi-log scale) (a) and transfer characteristics (b) of $0.12 \times 50 \mu \mathrm{m}^{2}$ AlInGaN/GaN HEMTs at RT (in blue) and $77 \mathrm{~K}$ (in black).

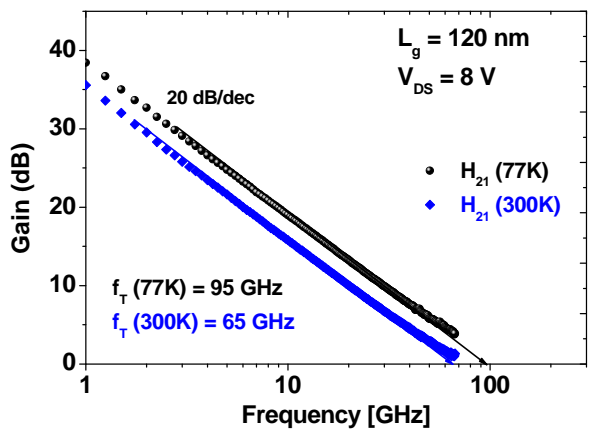

(a)

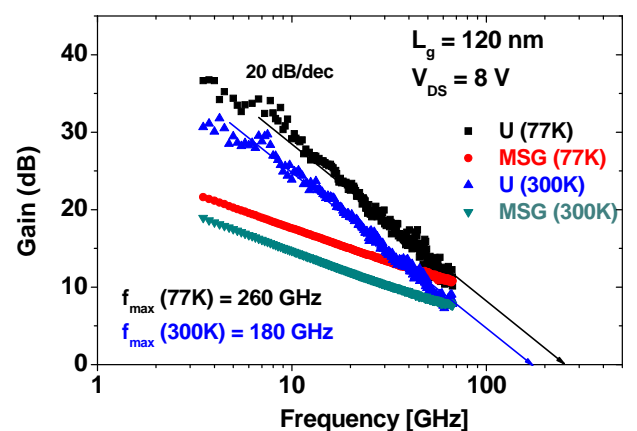

(b)

Figure 4. Current-gain (Figure 4a) and power-gain cut-off frequency (Figure $4 \mathrm{~b}$ ) at $V_{\mathrm{DS}}=8 \mathrm{~V}$ of a $0.12 \times 50 \mu \mathrm{m}^{2}$ AlInGaN/GaN HEMTs at RT (in blue) and $77 \mathrm{~K}$ (in black).

The increase in both $f_{\mathrm{T}}$ and $f_{\max }$ at $77 \mathrm{~K}$ is in good agreement with the transfer characteristics in Figure 3 as well as the studies reporting on low temperature behavior of GaN-based HEMTs in the literature $[15,16]$. It can be pointed out that RF performances are mainly limited by the access resistances due to rather high parasitic contact resistances.

\section{Conclusions}

Sub-10-nm ultrathin quaternary barrier $\operatorname{In}_{0.18} \mathrm{Al}_{0.70} \mathrm{Ga}_{0.12} \mathrm{~N} / \mathrm{AlN} / \mathrm{GaN}$ HEMTs capped with an in situ $\mathrm{Si}_{x} \mathrm{~N}_{y}$ revealed a smooth surface and high crystalline quality. Record 2DEG mobilities of $1800 \mathrm{~cm}^{2} \mathrm{~V}^{-1} \cdot \mathrm{s}^{-1}$ at RT and $7340 \mathrm{~cm}^{2} \mathrm{~V}^{-1} \cdot \mathrm{s}^{-1}$ at $4 \mathrm{~K}$ were achieved with a remarkably high carrier sheet density of $1.9 \times 10^{13} \mathrm{~cm}^{-2}$. The very high electron mobility in this ultrathin barrier heterostructure over the $4-400 \mathrm{~K}$ range is attributed to the reduced interface roughness owing to the implementation of an optimized AlN spacer layer and the use of an in situ-grown $\mathrm{Si}_{x} \mathrm{~N}_{y}$ cap layer. The DC and RF characteristics of the fabricated HEMT at $77 \mathrm{~K}$ reflected the outstanding high 2DEG electron mobility and very low sheet resistance at low temperature operation.

Acknowledgments: This work was supported by the French Defense Procurement Agency (DGA) under project EDA-EuGaNiC (European Defense Agency), the French RENATECH network and the National Research Agency under contract ANR-14-CE26-0022 (LHOM). 
Author Contributions: P. Gamarra, C. Lacam, M. Tordjman have grown the epilayers; E. Dogmus, R. Kabouche, S. Lepilliet, A. Linge, M. Zegaoui, and F. Medjdoub conceived, designed and performed the experiments; Hichem Ben-Ammar, Marie-Pierre Chauvat, P. Ruterana have performed the material analysis and TEM images.

Conflicts of Interest: The authors declare no conflict of interest.

\section{References}

1. Kuzmik, J. Power electronics on InAlN/(In)GaN: Prospect for a record performance. IEEE Electron Device Lett. 2001, 22, 510. [CrossRef]

2. Kohn, E.; Medjdoub, F. InAlN-A new barrier material for GaN-based HEMTs. In Proceedings of the International Workshop on Physics of Semiconductor Devices, 2007, Mumbai, India, 16-20 December 2007; pp. 311-316.

3. Gonschorek, M.; Carlin, J.F.; Feltin, E.; Py, M.A.; Grandjean, N. High electron mobility lattice-matched AlInN/GaN field-effect transistor heterostructures. Appl. Phys. Lett. 2006, 89, 062106. [CrossRef]

4. Liu, Y.; Egawa, T.; Jiang, H. Enhancement-mode quaternary AlInGaN/GaN HEMT with non-recessed-gate on sapphire substrate. IEEE Electron Device Lett. 2006, 42, 884-886. [CrossRef]

5. Makiyama, K.; Ozaki, S.; Ohki, T.; Okamoto, N.; Minoura, Y.; Niida, Y.; Kamada, Y.; Joshin, K.; Watanabe, K.; Miyamoto, Y. Collapse-free high power InAlGaN/GaN-HEMT with $3 \mathrm{~W} / \mathrm{mm}$ at $96 \mathrm{GHz}$. In Proceedings of the 2015 IEEE International Electron Devices Meeting (IEDM), Washington, DC, USA, 7-9 December 2015; pp. 9.1.1-9.1.4.

6. Gao, X.; Pan, M.; Gorka, D.; Oliver, M.; Schuette, M.; Ketterson, A.; Saunier, P. Ultra-thin barrier quaternary InAlGaN HEMTs with state of the art sheet resistance. Phys. Status Solidi C 2014, 11, 495-497. [CrossRef]

7. Hwang, J.H.; Kim, S.; Woo, J.M.; Hong, S.; Jang, J.-H. GaN HEMTs with quaternary In0.05Al0.75Ga0.2N Schottky barrier layer. Phys. Status Solidi C 2016, 213, 889-892. [CrossRef]

8. Ketteniss, N.; Khoshroo, L.R.; Eickelkamp, M.; Heuken, M.; Kalisch, H.; Jansen, R.H.; Vescan, A. Study on quaternary AlInGaN/GaN HFETs grown on sapphire substrates. Semicond. Sci. Technol. 2010, 25, 055012. [CrossRef]

9. Wang, R.; Li, G.; Verma, J.; Sensale-Rodriguez, B.; Fang, T.; Guo, J.; Hu, Z.; Laboutin, O.; Cao, Y.; Johnson, W.; et al. 220-GHz Quaternary Barrier InAlGaN/AlN/GaN HEMTs. IEEE Electron Device Lett. 2011, 32, 1215-1217. [CrossRef]

10. Lim, T.; Aidam, R.; Waltereit, P.; Henkel, T.; Quay, R.; Lozar, R.; Maier, T.; Kirste, L.; Ambacher, O. GaN-based submicrometer HEMTs with lattice-matched InAlGaN barrier grown by MBE. IEEE Electron Device Lett. 2010, 31, 671-673. [CrossRef]

11. Medjdoub, F.; Kabouche, R.; Linge, A.; Grimbert, B.; Zegaoui, M.; Gamarra, P.; Lacam, C.; Tordjman, M.; Forte-Poisson, M.F. High electron mobility in high-polarization sub-10 nm barrier thickness InAlGaN/GaN heterostructure. Appl. Phys. Express 2015, 8, 101001. [CrossRef]

12. Tulek, R.; Iygaz, A.; Gokden, S.; Teke, A.; Ozturk, M.K.; Kasap, M. Comparison of the transport properties of high quality AlGaN/AlN/GaN and AlInN/AlN/GaN two-dimensional electron gas heterostructures. J. Appl. Phys. 2009, 105, 13706. [CrossRef]

13. Wu, Y.F.; Kapolnek, D.; Ibbetson, J.P.; Parikh, P.; Keller, B.P.; Mishra, U.K. Very-High Power Density AlGaN/GaN HEMTs. IEEE Trans. Electron. Devices 2001, 48, 586-590.

14. Endoh, A.; Watanabe, I.; Yamashita1, Y.; Mimura, T.; Matsui, T. Effect of temperature on cryogenic characteristics of AlGaN/GaN MIS-HEMTS. Phys. Status Solidi C 2009, 6, S964-S967. [CrossRef]

15. Sensale-Rodriguez, B.; Guo, J.; Wang, R.; Verma, J.; Li, G.; Fang, T.; Beam, E.; Ketterson, A.; Schuette, M.; Saunier, P.; et al. Time delay analysis in high speed gate-recessed E-mode InAlN HEMTs. Solid-State Electron. 2013, 80, 67-71. [CrossRef]

16. Xue-Feng, Z.; Li, W.; Jie, L.; Lai, W.; Jian, X. Electrical characteristics of AlInN/GaN HEMTs under cryogenic operation. Chin. Phys. B 2013, 22, 017202. 